IFN Working Paper No. 1013, 2014

\title{
The Multi-Faceted Concept of Transparency
}

\author{
Jens Forssbæck and Lars Oxelheim
}




\title{
The multi-faceted concept of transparency
}

\author{
Jens Forssbæck* and Lars Oxelheim**
}

March 7, 2014

\begin{abstract}
Transparency has become a catchword and in the economic-political debate is often seen as a universal remedy for all sorts of problems. In this paper, we analyze and discuss the meaning and use of the concept of transparency in economic research. We look for common denominators across different areas where the concept is used, and find that transparency in essence is about reductions in information asymmetries, and therefore entails the transfer of information from a sender to a receiver. Transparency goes beyond mere information disclosure in that it has a demand-side dimension: the information transferred should be trustworthy and have a value to the receiver. We emphasize the distinction between ex ante transparency - related to predictability - and ex post transparency - related to accountability. In economics, increased transparency is mostly rationalized on grounds of improving efficiency, but sometimes transparency is properly viewed simply as a right to know. Complementarities between different types of transparency are pervasive, and its causes and effects typically co-determined - i.e. transparency is endogenous. As a means to improve competitiveness and economic growth, transparency of economic policy and corporate as well as institutional transparency interact. We challenge the view that more transparency is always better and argue for concave net benefits and the existence of optimal transparency, but optimality varies across policy areas, institutional settings, industries and individual firms.
\end{abstract}

Key words: Asymmetric Information, Transfer of Information, Moral Hazard, Adverse Selection, Transparency, Optimal Transparency, Ex Ante Transparency, Ex Post Transparency, Predictability, Accountability, Economic Policy, Economic Growth.

JEL: D82, E24, E27, E37, E38, E52, E58, E62, G38, M10

The authors thank VINNOVA and NASDAQOMX for generous financial support.

* Jens Forssbæck, KWC, Lund University, e-mail: Jens.Forssbaeck@fek.lu.se

**Lars Oxelheim, KWC, Lund University and the Research Institute of Industrial Economics (IFN), e-mail: lars.oxelheim@ifn.se 


\section{Introduction}

“Transparency” has become a catchword in the economic-political debate. The term is used and overused - sometimes perhaps misused. The catch-all nature and general positive ring of the concept are no doubt important reasons for its increased popularity, but a series of events and broad trends over the last couple of decades have also charged the concern for transparency in business, economics, and politics with real substance.

One starting point was the series of financial crises in emerging market economies in the mid-1990s - among them the Asian financial crises in 1997-98 - which were widely viewed as consequences of opaque corporate structures, weak institutions, and an insufficiency of accurate information on the true balance-sheet standing of firms as well as governments in these countries (see, e.g., Perotti and von Thadden, 2005; Hooper and Kim, 2007). But the more recent financial crisis also put the spotlight on the non-transparency of complex financial instruments and risk-taking in large financial institutions, and clearly showed that opaqueness in the financial sector is not just an issue in emerging markets (see, e.g., De Soto, 2012).

Another broad trend is the gradual change over the last decades toward more rule-based macroeconomic stabilization policies, which has incited a debate about the transparency of economic policy, and of the government bodies that execute it. The debate feeds on arguments raised both from the point of view of policy efficiency, and from that of democratic accountability. It initially bore primarily on monetary policy and central banking, but in recent years focus has increasingly shifted to the transparency of fiscal policy and public finances - not least following the sovereign debt crisis in Europe which has, for some countries, been linked to non-transparency (or downright fraud) in government accounts. Similar concerns have recently been raised regarding some emerging markets’ disclosure of macroeconomic outcomes. A more broad-based initiative for government policy transparency was the 
current U.S. administration's launch of its Open Government Directive in 2009 (see, e.g., The Economist, 2012).

Increasingly internationalized economies during the last decades have resulted in a correspondingly increased role of multilevel, supranational governance; which, in turn, has raised questions about traditional inter-governmental decision processes based on the strict sovereignty of nation states, and calls for more transparency and accountability in multilateral bodies, such as the IMF and the WTO. A short-lived surge in such calls in the early 2000s has gained renewed strength due to the role of, e.g., the EU and the IMF in managing the aftermath of the financial crisis, especially in the worst-hit countries (but this time with a more nationalist flavor). International organizations themselves, on the other hand, have whole-heartedly embraced transparency. The IMF's adoption of a "Code of Good Practices on Fiscal Transparency” is one example (IMF, 2007).

In the business world, a series of scandals in the early 2000s, both in the U.S. and in Europe (Enron, Tyco, WorldCom, Parmalat, Ahold, etc.), heightened interest in and attention to corporate governance, conflicts of interest between different stakeholder groups in the firm, and corporate social responsibility. Improved corporate transparency has been regarded as a primary remedy for such problems, and the attention has resulted in new regulation and codes of conduct in many countries, such as the Sarbanes-Oxley Act in the US (2002), the EU’s Transparency Directive (2004), OECD Principles of Corporate Governance (2004) and the UK Corporate Governance Code (2010). A related development is the increasing adoption worldwide of the International Financial Reporting Standards (IFRS) principles for corporate disclosure (2005), and the emphasis on information disclosure in the Basel rules for bank regulation (Basel 1-3, 1988-2011, the last accord to be implemented by 2018) - reflections of a trend toward increased convergence and transparency in, respectively, corporate financial reporting and disclosure of bank risk. 
Yet another broad reason for the increased interest in transparency is related to the rapid development of information technology. Among many other things - this development has been expected to increase price transparency, thereby boosting competition and enhancing the efficiency and integration of the goods and services markets, both at the retail and at the intermediary levels.

From its use in the political-economic debate it is not always very clear what exactly transparency means, except that it has to do with openness, clarity and accessibility of information, communication, etc. But as the concept of transparency - or one should perhaps more fittingly talk of the "idea” of transparency, including all its promises and positive connotations - has gained increasing general popularity, it has also seeped its way into academic research in a broad range of social science disciplines.

As in everyday usage, media reporting, and the "speak" of policy-makers and business leaders, transparency in social sciences can have different meanings, rationales, and implications. The purpose of this chapter is to make an overview of the definitions and use of the concept of transparency in economics and business research in particular. An initial caveat is warranted. The "take" on transparency in economic research rests on different, but often related, sources and research traditions - accounting, corporate finance, development economics, institutional economics, monetary economics, public economics, and more. But framing transparency in terms of basic concepts in the economics of information makes the potential application of transparency in economics practically limitless. Any problem that incorporates the idea of asymmetrically distributed information between different economic agents makes an assumption about transparency, and is potentially affected by altered assumptions about it.

Asymmetric information is at the very core of agency relationships, adverse selection problems, intermediation, signaling, the economics of trust and reputation, etc. All are based on the notion that rational, self-interested individuals - when equipped with infor- 
mation that others do not have - will make economic decisions that result in inefficiencies, market failures, or at the very least outcomes that are different (and typically "worse”) as compared to the full-information Arrow-Debreu world. We can therefore not hope to make a comprehensive survey of all relevant literature in the area. The chapter is, rather, an attempt to provide a structure to our thinking about transparency, and to weed out some common denominators in the various ways it has been used so far in economic research.

The paper is organized the following way. In Section 2 we make an attempt to delineate the meaning(s) of transparency as used in economics and business research. The broadness of the term makes a strict and universally viable definition virtually impossible; what we go for here is instead to trace out a number of requisites which make the identification of a few main aspects of transparency possible. In Section 3 we discuss possible rationales for transparency. The general intuition is that transparency is “good”. But why? What are the desiderata that transparency is supposed to achieve (or is it an end in itself)? Section 4 further discusses the effects of transparency, including a brief review of empirical results in some key areas. In Section 5 we elaborate on the existence of “optimal” transparency, based on the general insight that transparency has costs as well as benefits, and that the net benefits may not be monotonically growing in transparency. Section 6 summarizes.

\section{The meaning of transparency}

There are many possible ways to slice the concept of transparency. Corporate transparency is distinct from the transparency of government policy. Transparency about the government’s policy decisions is distinct from transparency about the processes and procedures by which these decisions are reached. There can be varying degrees of transparency between different geographical markets, at different levels of government, in terms of the extent to which prices 
in a particular market are informative about fundamental values or underlying demand and supply conditions, etc.

One way to get an initial grasp of the concept is to review a few broad, general definitions. For instance, according to the OECD, “[b]udget transparency is defined as the full disclosure of all relevant fiscal information in a timely and systematic manner” (OECD, 2002, p. 7). The WTO’s glossary defines in 2014 transparency as the "degree to which trade policies and practices, and the process by which they are established, are open and predictable.” UNCTAD (2012) defines transparency as "a state of affairs in which the participants in the investment process are able to obtain sufficient information from each other in order to make informed decisions and meet obligations and commitments” (p. 7).

Some common denominators can be distinguished. Clearly, the initial state is that an agent has access to information that others do not have. Information (about a budget, a policy, a decision-making process) is then made available for observation by others. The information made available should be relevant and possible to use as a basis for decisions, and the manner in which it is made available should be systematic. Transparency is associated with openness and - at least when referring to policies or practices - predictability.

It thus seems reasonable to identify the existence of information asymmetries as a key prerequisite for a meaningful discussion of transparency. Individuals make decisions based on public information (freely available to all) and private information (available only to some). Assuming that the private information is relevant for decision-making, and that some have it and some do not (but would like to have it and know others have it) the asymmetries in the distribution of information will affect decisions made and therefore economic outcomes.

The mere existence of information asymmetries is not sufficient for the discussion to completely add up, however. In addition, there has to be some mechanism for (more or less) information to be transferred; there has to be some scope for changes in the extent of 
information asymmetries. Only then is it possible to discuss the objective, or the rationale, for transparency, its benefits, possible costs, and net effects. This view of transparency also suggests that full transparency is the absence of information asymmetries. This does not necessarily imply perfect information - even with full transparency there can still be incomplete (public) information, but no one has the advantage of being better (privately) informed.

The notion of an information transfer taking place suggests the existence of a sender of information, and a receiver of information. A particularly clear example of this type of situation is a basic signaling game, where the terminology of sender and receiver of information is frequently used. Two actors have access to different information, the sender makes a decision if, how, and what information to transfer to the receiver, who - in turn - makes a decision how to interpret the information transferred. The key concern of signaling is that of reducing information asymmetries, and the application of this basic idea since Spence’s (1973) seminal work on job market signaling is enormous (see, e.g., Riley, 2001, and Spence, 2002, for reviews of the theoretical progress in the area). In practice, however, the senderreceiver relationship is rarely this clear-cut. In a wide range of situations where transparency is discussed, there are multiple actors, and third-party considerations may dramatically change the cost-benefit analysis of reducing information asymmetries compared to the simplest situation with one sender and one receiver. (We give several examples in Section 5; a straightforward example might be the case where a firm's disclosure of more information is beneficial by reducing information asymmetries vis-à-vis investors, but harmful by revealing competitive advantages to rival firms.).

What might the information being transferred, or signaled, be about - in general terms? Stiglitz (2000) argues that there are two particularly important types of information: information about characteristics (or quality), and information about behavior (or intent). Asymmetries with regard to these two types of information broadly correspond to two main 
types of problem resulting from imperfect transparency - adverse selection (problems of choice, given different abilities of transacting parties to observe the characteristics of the product transacted), and moral hazard (problems related to the action taken by a counterparty in a transaction). ${ }^{1}$ They cover a wide range of situations where transparency may be an issue from the "lemons" problem in goods and services markets (Akerlof, 1970), via financial markets where similar adverse selection problems occur when there are both informed and uninformed traders/investors (de Long et al, 1990), from the job market selection problem when employers have imperfect information about applicants' ability (the area of application of Spence’s original 1973 signaling article) to the near-universal view of the investor-firm (owner-manager) relationship as that of principal and agent (Jensen and Meckling, 1976). Similarly, in analyses of (economic) policy, a principal-agent view is frequently adopted (e.g., Besley, 2007). In principal-agent relationships, such as that between owner and manager, employer and employee, or government official and polity, (lack of) information about quality (ability, or "type") or intent (hidden action) is often framed in terms of information about the agent's “effort”, but it is largely a matter of differences in terminology rather than substantive differences in meaning.

Thinking about transparency as reductions of asymmetries in information about quality and intent clearly has wide application. But it is not sufficient for a comprehensive view of transparency. Information about both quality and intent are examples of ex ante transparency. Imperfect transparency with regard to either introduces an uncertainty which affects incentives and decisions and therefore outcomes; variations in transparency may affect how efficient these outcomes are (or can be). Because imperfections in ex ante transparency intro-

\footnotetext{
${ }^{1}$ Sometimes the distinction between adverse selection and moral hazard is framed as a timing issue: adverse selection is about the ex ante choice of contracting terms when one of the contracting parties has more information, moral hazard is about the counterpart's actions once the contract has been entered into.
} 
duce uncertainty, it is strongly associated with predictability. But there can also be imperfect transparency ex post about the actual outcomes. Applying the principal-agent view to policy analysis makes a clear example. Delegated decision-making in a representative political system can be viewed as a principal-agent relationship where the electorate is able to discipline the government by the threat of removal from office. The "information transmitted" is the extent to which the public (principal) observes policy choices and processes (“effort”), but also the result (outcome) of the government's (agent's) decisions. ${ }^{2}$ Analyses of government policy transparency often emphasize this latter type of ex post transparency, which is distinct from transparency in terms of information about quality or intent, because it is strongly associated with accountability - the notion of the principal holding the agent accountable for the consequences of his actions. ${ }^{3}$ This could be rephrased as a problem of contract enforcement imperfect observability of the result diminishes the principal's ability to sanction the agent for failure to accomplish what was agreed upon. ${ }^{4}$

\footnotetext{
${ }^{2}$ The observability of policy choices and decision-making processes can be rephrased into a distinction between transparency of policy content (information about the decisions made, the "substance" of the policy pursued) and procedural transparency (information about the processes whereby decisions are reached). In many situations, it may also be instructive to separate between de jure policy transparency (information about the policies decided upon) and de facto policy transparency (information about the degree to which these policies are actually implemented or enforced).

${ }^{3}$ Welfare improvements may even rely more strongly on transparency of outcome because ex ante transparency may not be particularly effective at disciplining governments if voters do not know what the optimal policy is (see Prat, 2005).

${ }^{4}$ Besides information about quality, intent, and outcome, one additional type of information requires mention: information about scarcity - the extent to which prices in competitive, decentralized markets convey all relevant information to achieve the efficient allocation of scarce resources. In essence, this is an outcome. In a world of perfect information and complete markets, the price is all that is required to achieve efficient resource alloca-
} 
Connelly et al. (2011) argue that a key property for a signal to be efficacious is that it is "observable", and link observability to terms that lie close to the common, everyday understanding of transparency, such as "clarity”, "visibility”, and "absence of distortion”. Parts of the literature also emphasize concepts like "receiver attention” (the extent to which the receiver is looking for the information, or knows what to look for) and "receiver interpretation” (processing the received information into meaningful knowledge). This emphasis on how the information is received suggests, we argue, an important distinction between transparency and mere disclosure of information in general, namely that there is a demand-side dimension to transparency. Transparency presumes that the information transferred is properly received and processed - i.e., not just that the information is there, but also that it gets there.

In what way is the demand side taken into account in the common understanding of transparency? In the initial broad definitions of transparency that we reviewed at the beginning of this section, it is reflected by the invocation of various adjectives postulating that the information made available should be "relevant”, "timely” and "sufficient [...] to make informed decisions”. The same conditions (“relevant”, "reliable”, "timely”) recur in the area of corporate transparency - particularly in codes and standards for financial reporting and disclosure (see, for instance, Forssbaeck and Oxelheim, forthcoming, Chapters 17, 22 and 23). Sometimes the receiver's perspective is accounted for differently - for instance, Ghauri et al. (in Forssbaeck and Oxelheim, forthcoming, Chapter 16) argue that “transparency encompasses evaluation by 'surrounding units’”, whereas Plummer and Tafti (in Forssbaeck and Oxelheim, Chapter 7) note that transparency has more effect when there is an incentive for users to act on the information. The receiver perspective is emphasized in both cases. and Stiglitz, 1986). 
Another way of wording the requirement that the information transferred should be reliable is to say that the receiver must be able to trust the information (as noted in Forssbaeck and Oxelheim, Chapter 24), which brings up another qualitative aspect of the information transferred: improved transparency can be understood along the lines both of transferring information that scores higher in terms of reliability, decision-relevance, etc., and of simply disclosing more information. In the corporate finance literature, theoretical models often allow "improved disclosure" or "improved transparency" to be interpreted as increases in either the quantity or the quality (precision) of the information, or both (see Easley and O’Hara, 2004, and Hermalin and Weisbach, 2012, for two examples). This does not mean that the distinction is unimportant - on the contrary: conceptually, it can be crucial. In Section 5, we will review examples both of situations where the precision of the information determines the optimal quantity given of it, and where a higher quantity of information may be suboptimal simply due to information processing costs.

A natural criterion for the information transferred to be both relevant and sufficiently precise (or trustworthy) is that the receiver attaches some value to it. But if the information is valuable to the receiver, it may also indicate that providing the information is costly to the sender. Thus, sender and receiver may have very different views on the desirability of bridging the information gap. Indeed, taking into account the possibility of non-alignment of incentives is central not just for understanding the effects of the information asymmetries and conflicts of interest as such, but also for a meaningful discussion of why there is, or should be, more or less transparency.

Holmström (1979) defines a valuable signal as a signal which, if included in a risk-sharing contract, can make both the principal and the agent strictly better off than if the contract is based solely on outcome (payoff) - i.e., a Pareto improvement. Holmström’s definition refers specifically to principal-agent relationships, but is instructive in that it succinctly 
pinpoints the need for a clear idea of what transparency is supposed to achieve, and also gives an idea of why we might see more or less transparency in different areas. We will discuss the rationale for, as well as the determinants of, transparency in the next section, but first let us review what we have found so far.

In summation, then, a meaningful discussion about transparency requires the existence of information asymmetries (asymmetric distribution of private information between different economic actors), but also some mechanism for information to be transferred from actors with private information (“sender”) to those that do not have it (“receiver”). Increases in transparency correspond to reductions in information asymmetries. Information could be about quality or intent (both of which could be related to “effort”) - ex ante transparency but also about outcomes - ex post transparency. Transparency goes beyond mere information disclosure in that it has a demand-side dimension, which requires that the information transferred should be not just observable by the receiver, but also relevant for her decision-making. A related qualifier for a meaningful discussion about the desirability and effects of transparency concerns the precision (or quality) of the information transferred. Transparency can be associated simply with more information, but does not have to be if this information is irrelevant or insufficiently precise. Decision-relevance and sufficient precision imply that the receiver attaches value to the information transferred, which could (and typically does) also mean that providing the information is costly to the sender.

\section{The rationale for transparency}

Discussing the rationale for transparency is about specifying an objective function. Beyond the positive ring of the concept and the general intuition that transparency is "good", there has to be some sense of what transparency is supposed to achieve - what it is good for. Taking the broad view, we see essentially two main categories of objectives. 
The first is functional, or instrumental. This category of objectives takes many forms, the most general of which is to increase efficiency in terms of overall welfare. Such efficiency improvements can be reached in many different ways - by increasing competition, by reducing uncertainty and transaction costs (including search and information costs), by alleviating coordination failures, and by making markets more complete. Other objectives in the instrumental category might be to improve effectiveness (e.g. of a particular policy), or just generally to attain some benefit, which - more often than not - is measurable. The objective may be concrete and specific (for instance, in corporate finance the objective is usually to maximize firm value) or broader and more vague (for instance, in the EU’s Lisbon Strategy transparency, in the form of the Open Method of Coordination, was intended to create peer pressure for policy reform with the ultimate goal of making European economies more competitive). The point is that when the rationale is instrumental, transparency does not really have a value in itself - it is simply a means to an end.

The second broad category is more value-driven, and concerns ideals such as democratic accountability or legitimacy, but also adherence to social contracts or norms within a society. It is often more applicable to the transparency of public policy than to, say, corporate transparency (especially policy areas that are less "technical” and of greater concern to the general public). We are here much closer to transparency as an end in itself - of transparency as a "right to know” (cf. Stiglitz, 1999). The instrumental/efficiency rationale is by far the most important one in economic research, however, especially when transparency is viewed as a microeconomic question of information distribution that affects resource allocation. In the information-theoretic literature, the criterion for an efficiency improvement is also strict, viz. that of constrained Pareto efficiency (essentially whether the decentralized market allocation can be improved upon in a Pareto sense, given the existing market imperfections cf. Holmström’s, 1979, definition of a valuable signal in the previous section). But also in 
more narrow or empirically oriented applications, when the objective is less clearly linked to welfare improvements in a strict microeconomic sense, the benefit that transparency is intended to achieve is typically measurable.

The boundary between instrumental (efficiency-based) and more value-driven rationales is not always strict. For instance, in political science and public economics, transparency is typically understood in broad terms and encompass the extent to which government bodies are willing and able to provide information regarding their decision-making processes and policy choices, collection and dissemination of credible information about policy outcomes, but also, e.g., the freedom and reach of the media (see, for instance, Hollyer et al., 2011). The rationale is to ensure accountability of government, which can clearly be motivated on the basis of democratic ideals, but also on efficiency grounds insofar as accountability disciplines government officials to make better and more efficient policy decisions.

Similarly, transparency of MNEs about issues and activities related to Corporate Social Responsibility (CSR) can either be seen as motivated by a true concern for principles other than those of firm value maximization, or as a way to signal conformity with the norms and values of the society with the ultimate objective of reaping positive financial payoff from doing so (or avoiding negative consequences of deviating) - a "single bottom line” masquerading as a double one.

Nor are instrumental and value-driven rationales for transparency mutually exclusive in any given situation - they can co-exist. Where either could enter as outcome variables in an objective function, they could be in conflict, but need not be. For instance, both ex ante and ex post transparency may be important to create accountability and legitimacy for government policy, but transparency of government decision-making processes may also improve the public's ability to predict and respond to policy actions - thus, ex ante transparency (predictability) may be welfare-increasing in terms of other rationales than that of accounta- 
bility/disciplining. Another example might be the rationale of transparency as a way to engender trust, which lies somewhere in between purely value-driven considerations and efficiency maximization. ${ }^{5}$ A relationship characterized by trust may be viewed as "morally" or socially more desirable than one characterized by distrust - a norms-based motivation for transparency; but trust can also be viewed as a means to reduce transaction costs to the extent that distrust causes frictions, and is therefore efficiency-enhancing. We will return to the relationship between transparency and trust below.

In other policy areas, the motivation for a public policy - though in a formal sense resting on the existence of market failures - may in the public mind be related more strongly to very different considerations. One such area may be education policy. Even if the existence of positive externalities causing socially suboptimal underinvestment in education is a sufficient argument for a public education policy, the average citizen probably wouldn’t frame it like that. He or she is more likely to perceive equal opportunity for at least primarylevel schooling as a basic, inalienable human right. The rationale for transparency in policies related to the public school system cannot be entirely independent of such considerations. Thus, increased transparency may or may not make sense from the point of view of making public education policy more effective at alleviating market failures, but the fact that the public perceives education as a matter of general concern may be sufficient to motivate transpar-

\footnotetext{
${ }^{5}$ One particularly clear example of an area where trust matters, and transparency plays a role, is that of public procurement, the idea of which is to expend public resources as efficiently as possible by taking up offers from a range of producers and choosing the best offer. But for this process to provide the expected efficiency benefits, there needs to be trust on the part of producers in the fairness of the procedure and a belief in the integrity of the procuring public body. In other words, there has to be a minimum level of procedural transparency for the best producers to be willing to file an offer. (Incidentally, the level of transparency is a tradeoff, since excessive information provision may distort the competitive nature of the process and invite collusion - see Forssbaeck and Oxelheim, forthcoming, Chapter 6)
} 
ency. Again, sometimes people just have a "right to know” (see Forssbaeck and Oxelheim, forthcoming, Chapter 9).

The rationales for transparency that we have discussed are motivations for (various types of) transparency based on the perceived benefits of greater information availability and dissemination in different areas. But this is only half the story. The actual levels of observed transparency vary greatly, regardless of area and regardless of whether comparisons are made across countries, across firms, between different government agencies, markets, etc. So what are the determinants of transparency?

One crucial determinant of transparency is the set of incentives facing the actors. We have already argued in Section 2 that sender and receiver may have different views on the desirability to reduce information asymmetries. A first question to ask is therefore whether the actor possessing the private info has incentives against transferring information to the informationally disadvantaged counterpart? If not - if both actors have near-identical objectives and these are better met with a greater amount of information exchange - there is little reason to suppose that transparency should be any less than near-optimal. Spence (2002) notes that "signals are not terribly complicated things in games where the parties have the same incentives, i.e., where there is a commonly understood desire to communicate accurate information to each other” (p. 434). Thus, if the sender and receiver have the same objective, the appropriate amount of voluntary transparency will tend to occur spontaneously as a mechanism to extract the mutual benefits of leveling the information playing field.

Such can typically not be assumed to be the case if private information is valuable. For instance, agency relations are commonly understood as relations where principal and agent have different individual objectives, and the principal cannot easily determine if the agent takes action in line with the principal's objective or pursues self-interested behavior (i.e., the principal lacks information about the agent's intent). In a principal-agent relation- 
ship, the importance of incentives often boils down to the question whether the agent can obtain private benefits from being less transparent (this is discussed in the context of banking regulation in Forssbaeck and Oxelheim, forthcoming, Chapter 12).

But even when being transparent provides benefits in an absolute sense to the sender and there are no private benefits from being opaque, transparency may be limited due to the costs of information provision. As a very simple and stylized example, consider a typical signaling game setup with adverse selection. Suppose, for instance, that there are two types of firms, high- and low-quality firms, both with opportunities to engage in costly signaling. High-quality firms may benefit from signaling its quality to investors (via higher valuation and lower cost of capital), but if low-quality firms can mimic this signal (produce a "false signal”), the benefits of signaling may not outweigh the costs for a high-quality firm. Only if a high-quality firm can distinguish itself from the low-quality firms will "being transparent" pay off. Thus, the relative costs of information provision are an important determinant of (the incentives for) transparency - also where there is no value of secrecy.

The importance of incentives and relative costs, as well as expected payoffs/outcomes, in determining the level of transparency essentially suggests that the determinants and the effects of transparency are, at least partially, simultaneously determined - in short, transparency is endogenous. In the simple example above, the benefits of increasing transparency are never realized, because the beneficial effects of signaling are insufficient to motivate the investment in further information provision - thus, the (expected) effect "causes" the level of transparency.

Friberg (in Forssbaeck and Oxelheim, forthcoming, Chapter 13) addresses similar endogeneity issues in the context of transparency of prices on similar products in different geographical markets. Increased price transparency facilitates arbitrage between markets, suggesting potential welfare gains. But the producer's choice whether or not to make prices 
more transparent is not independent of the likely consequences of such arbitrage, so again, outcome and cause are co-determined. Yet another example might be corruption (see Forssbaeck and Oxelheim, forthcoming, Chapter 15). The extent to which government officials are willing to provide information regarding their decision-making processes depends partly on the extent to which they extract illegitimate private benefits from not doing so - i.e., the level of corruption; conversely, the feasible scope for corruption depends on the level of transparency.

Regulation mandating increased transparency may be motivated on welfare grounds when market failures prevent the sender from providing a socially optimal amount of information. In practice, such regulation is an extremely important determinant of the actual levels of transparency observed (one need only think of the elaborate systems of standards for corporate disclosure). But regulation that runs counter to the information provider's incentives may also result in avoidance strategies, opportunism, or even information manipulation, thus creating additional welfare losses (see further Section 5).

Not just (economic) incentives, costs/benefits and regulation are related to transparency, but also social norms and perceptions of what's "fair” and "right”. This has implications for (i) the rationale for transparency (as discussed above), insofar as there exist value-based arguments in favor of transparency, and values and norms vary with the social context (see, e.g., Forssbaeck and Oxelheim, forthcoming, Chapter 16); (ii) the determinants of transparency: the sender may have certain incentives, but there may be social pressure for increased transparency - e.g., public outrage after corporate scandals or corruption incidents such that regulation mandating increased transparency is invoked whether or not this is motivated on welfare or efficiency grounds; (iii) the effects of transparency: transparency may affect an agent's propensity to engage in activities that increase the principal's utility even 
when there are no strict incentives (or even disincentives) to do so, because it’s “fair”, or because it is what others (are thought to) do.

For instance, Irlenbusch and Sliwka (2005) study the influence of transparency (defined as revealed effort) on reciprocity and fairness concerns in an experimental setting. They conclude that transparency does not necessarily increase average effort, but makes agents exert more similar levels of effort. This could be interpreted as tentative support - which, arguably, is the best that economic research can offer at present - for the notion that greater transparency more generally leads to greater adherence to prevailing norms and higher levels of social cohesion (also see Frey, 1998).

As we have argued above, transparency requires trust - the recipient of information must believe the information received to value it and to act on it. But if transparency positively influences reciprocity, fairness, and social cohesion, then it's also possible to turn the argument around: transparency fosters trust. ${ }^{6}$ Trust is associated with beneficial economic outcomes, because distrust (like opaqueness) causes frictions and transaction costs. For instance, Aghion et al. (2010) show that distrust creates demand for high levels of government intervention in the economy, even when such intervention is corrupt and ineffective; high levels of intervention, in turn, discourages the formation of trust. Thus, they demonstrate that beliefs (trust) and institutions (regulation) co-evolve. One could possibly make the leap to infer a similar co-evolution between transparency and adherence to social norms (in terms of, e.g., firms not engaging in activities that impose social costs on others in the sense of Coase,

\footnotetext{
${ }^{6}$ Conversely, one can easily make anecdotal and intuitive cases for an association between lack of transparency and distrust. For instance, in the area of corporate transparency (the way we mostly understand it here, i.e., in terms of financial reporting and disclosure) Goldman and Slezak (2006) note that "corporate scandals (e.g., Enron and WorldCom) have created a widespread perception that the financial and accounting disclosures provided in a corporate culture fixated on stock price performance cannot be trusted” (p. 604).
} 
1960, civil servants not engaging in corruption, etc.). To the extent that transparency - in a broad sense - has the capacity to shape beliefs, trust, and social cohesion, there may be considerable complementarity effects determining the level of transparency.

The difficulties posed by such complementarities (cf. the endogeneity issue raised earlier) are reflected in available empirical research. As observed by Glennerster and Shin (2008), transparency (especially policy and regulatory transparency) is often broadly associated with better institutions and good governance in general, and in empirical studies often bundled together or tested using indirect measures, causing ambiguity as to causality. Convincing attempts to disentangle what causes what are surprisingly few, regardless of which type of transparency is considered. For instance, Wehner and De Renzio (2013) remark that "hardly any effort has been invested in exploring the determinants of fiscal transparency" (p. 96). In their own study they use a relatively narrow measure of budget transparency, and find that it is primarily affected by free and fair elections and by political competition.

Similarly, Bushman et al. (2004) argue that there is a paucity of research on how and why corporate transparency varies between countries. In their empirical work, they study two facets of corporate transparency, governance transparency and financial transparency, and find that the former is associated primarily with higher judicial efficiency and the latter primarily with political-economy factors, such as low state ownership in the corporate sector and low risks of expropriation. Thus, their work to some extent confirms the intuition of a high degree of correlation between different types of transparency, and an association between transparency and other benefits, such as efficiency and high-quality institutions. This naturally brings us to the effects of transparency. 


\section{The effects of transparency}

There is a wide-spread perception that greater transparency is beneficial. For instance, the Bushman et al. (2004) paper just referenced notes that the availability of information is usually considered "a key determinant of the efficiency of resource allocation decisions and growth in an economy" (p. 208). Moreover, "transparency, in addition to improving the allocation of resources, can make governments more accountable, undermine the power of special interests, and thus lead to improved policies and institutions” (Glennerster and Shin, 2008, p. 184). This sounds compelling, but is rather imprecise. We argued above that the "efficiency rationale" for transparency is the most important (but not the only) one in economic research, and it is the one we will focus on in the discussion of the effects of transparency below.

It should perhaps be made clear from the onset that transparency is no panacea for inefficiency. The question of the effects of transparency - the way we have interpreted it here as essentially reductions in information asymmetries - is the reverse of the question of what problems the information asymmetries give rise to. These are many, and very varied, but possible - as we have argued - to sort into the broad categories of selection and agency problems (associated with imperfect ex ante transparency) and accountability or enforcement problems (associated with imperfect ex post transparency). Such problems give rise to market failures related to incompleteness of markets, imperfect competition, coordination failure, etc. But market failures occur for many reasons (imperfect public information, the nature of the good or service exchanged in the market, externalities, transaction costs, other endogenous and exogenous factors determining market structure, including, e.g., geography), some of which are associated with information asymmetries, and some of which clearly are not. Because information asymmetries are not the only thing giving rise to market failures, increased transparency cannot be a patent solution. 
Moreover, even where information asymmetries are at the heart of the issue, and a feasible mechanism for transferring information from the informed to the uninformed exists (which is not necessarily always the case), it may be excessively costly. Other competing mechanisms to come to terms with the problems caused by the information asymmetries may then be available - taxation or subsidies, design of contracts and price schedules, incentive schemes connected to outcomes or relative outcomes (yardstick competition, benchmarking), or other monitoring or regulatory technologies than that of making private information public. It is not given that measures to improve transparency always dominate these alternative measures, given the myriad different situations - large and small - in which information asymmetries occur.

All this said, Geraats (in Forssbaeck and Oxelheim, forthcoming, Chapter 3) makes a useful distinction between incentive effects - the way transparency affects ex ante behavior by changing the information structure - and information effects - the ex post consequences of making a certain piece of information available. These are closely related to the notions of ex ante and ex post transparency. Holding on to that distinction, we may argue that transparency has two overarching potential effects: to increase predictability, and to strengthen accountability (or, differently put, contract enforceability). ${ }^{7}$ It shouldn’t come as a surprise that transparency is hard to disentangle from institutional quality and good governance more generally.

\footnotetext{
${ }^{7}$ It should be noted that the distinction between incentive effects and information effects does not strictly correspond to that between predictability and enforceability, but cuts across these categories. Contract enforceability, for instance, or the knowledge that ex post outcomes will be made public ex post, clearly affects ex ante incentives and behavior (disciplining). Conversely, ex ante transparency (e.g., about a procedure, a regulation, a policy rule, etc.) has direct information effects by reducing transaction (search and information) costs.
} 
How does this bear on growth, for instance (cf. the Bushman quote at the beginning of the section)? The tenet of modern, endogenous growth theory (see, e.g., Lucas, 1988; Romer, 1986, 1990) is that growth is the result of technological change driven by rational (human and/or physical capital) investment decisions by private agents who respond to economic incentives, but also institutions are widely recognized to play an important role for economic performance. ${ }^{8}$ In theory, the strongest argument for a role of institutions in economic growth is that institutions, while necessary for economic exchange in various forms, can exhibit varying degrees of efficiency. Less efficient institutions result in higher transaction costs, thus reducing value-added for a given level of factor inputs. Institutional improvements and innovations raise the efficiency of economic interaction between agents, and therefore increase growth.

Matthews (1986) makes the analogy between institutional change and technological change as sources of growth: transaction costs and production costs are two pieces of a pie - both inescapable realities of economic activity. Innovations that decrease either type of cost for a given level of output are innovations with potential to raise the growth rate. ${ }^{9}$ We might add information asymmetries as an inescapable reality of economic activity, or we might view lack of transparency as a transaction cost (for instance, the pervasiveness of market failures due to lack of transparency/information asymmetries implies that prices in decentralized markets do not generally convey accurate information about scarcity, and that markets

\footnotetext{
${ }^{8}$ For a more comprehensive discussion of growth theory as related to transparency and institutions, see Forssbaeck and Oxelheim (2006). Also see Frey (1990) and North (1990).

${ }^{9}$ While theory emphasizes the dynamic aspect of institutions, the empirical literature typically makes indirect inferences about the effects of institutional improvements through cross-sectional studies of the level of institutions and their association with average growth rates and/or income levels (see, e.g., Barro, 1991, 1997; Rodrik et al., 2004).
} 
are generally at least partially segmented, which causes transaction, e.g. search, costs). The categorization is less important - the point is that insofar as improved transparency raises efficiency (especially the efficiency of investment in new technology), it has the potential to raise growth. Lack of transparency - in terms of poor predictability and accountability - is costly.

Some channels are better understood than others. One area where the effects of corporate transparency are theoretically straight-forward, and which also provides a particularly lucid illustration of the link to economic growth, is its impact on firms' cost of capital. Information asymmetries between the firm's insiders and their outside owners and creditors give rise to agency problems and credit rationing, and information asymmetries between potential investors create adverse selection problems (uniformed investors fear trading against those with private information, which reduces the willingness to trade and causes illiquidity and financial market incompleteness). As a consequence, firms must issue equity and debt at a discount, i.e., at a higher cost of capital. Increased corporate transparency reduces information asymmetries between firms and investors and/or between different potential investors, thus decreasing the cost of capital and expanding the set of positive net present value investment projects. ${ }^{10}$ Both agency and adverse selection problems in capital acquisition also make firms financially constrained, and financially constrained firms facing incomplete financial markets tend to be more risk averse (in near-complete financial markets with few constraints, on the other hand, risk-sharing works

\footnotetext{
${ }^{10}$ Theoretical results on the link between corporate transparency and the cost of capital include Diamond and Verrecchia (1991), and Easley and O’Hara (2004). Recent empirical studies include Leuz and Verrecchia (2000), who make use of shifts in the transparency regime (in the form of disclosure standards) to address the endogeneity issue; Greenstone et al. (2006), who similarly exploit a legal shift to identify the effects of mandatory disclosure; and Leuz and Schrand (2009), who approach the issue from the opposite direction, and investigate the disclosure effects of the cost-of-capital shock created by the Enron scandal. Also see Healy and Palepu (2001) for a survey.
} 
efficiently and firms have less reason to be risk averse). The consequences are diverse and potentially far-reaching, not least for investment in innovation (see Forssbaeck and Oxelheim, forthcoming, Chapter 10).

In particular, financial constraints make investment sensitive to financial variables (Hubbard, 1998), with knowledge-intensive investment being particularly sensitive (Forssbaeck and Oxelheim, 2011). Higher risk aversion in firms also leads to greater sensitivity of investment activity to cyclical swings, and to price and wage rigidities (see, e.g., Chevalier and Scharfstein, 1996). Greater corporate transparency not only alleviates financial constraints, but also implies more efficient risk-sharing and more risk-neutral firms, suggesting that investment in lowprobability outcomes (representing potential technological breakthroughs) can be financed, whereas greater institutional transparency in the shape of increased predictability and contract enforcement implies lower uncertainty of appropriation of returns to investment in innovation/knowledge. ${ }^{11}$

Exemplifying with financial market incompleteness and investment thus highlights the complexity of the interactions between different types of transparency in the determination of more aggregate economic outcomes. Information asymmetries between firms and investors affect financial market incompleteness, but so do a lot of other types of information asymmetries. For instance, during the 1990s, a wave of literature emerged emphasizing the role of legal institutions (including, e.g., investor rights and contract enforceability, related to both the ex ante and the ex post dimensions of transparency as we have defined it) for financial development (see, e.g., La Porta et al., 1998) - clearly suggestive of the complementarity of different types of transparency and the potential knock-on effects of improving transparency in different areas.

\footnotetext{
${ }^{11}$ Wurgler (2000) provides evidence of a positive association between capital allocation efficiency and firmspecific information in stock returns on the one hand, and institutional transparency on the other.
} 
Yet another example of how transparency affects investment is its potential effects in international capital flows, where excessive investment flows in and out of emerging markets have been explained in terms of a "coordination effect”: insufficient transparency implies that investors cannot effectively discriminate between firms/borrowers indicating that small pieces of negative information can have disproportionate effects and cause investors to withdraw funding from an entire market. The mechanism has been used to explain financial crises, speculative attacks, to motivate the lender-of-last-resort function of the central bank, etc. (see, e.g., Rochet and Vives, 2004). Similarly, in the case of the Lehman Brothers crash in the early phases of the latest global financial crisis, insufficient transparency meant that banks could not effectively discriminate between counterparties, causing the whole interbank market to freeze up. A possible effect of greater transparency in light of this type of coordination failure would be lower susceptibility to crises.

Policy-oriented applications of growth theory directly or indirectly recognize the role of both institutions and transparency for economic growth. For instance, the World Economic Forum’s Growth Competitiveness Index (see Sala-i-Martín et al., 2013), includes among the key "pillars” of growth the quality of institutions and the stability of the macroeconomic environment, as well as goods and labor market efficiency, and financial market development. Transparency thus influences productive investment, and thereby economic growth, at the level of economic policies affecting investment decisions, via the markets (including their institutional and regulatory structure) in which investments are made and funded, and down to the level of individual firms that ultimately make the investment decisions. These three levels roughly coincide with the division of this book into three parts - policy, market and institutional, and corporate transparency.

Availability of empirical research on specific effects in different areas (beyond the ones already mentioned) varies substantially. Here, we can only give some suggestive 
hints. Moreover, as mentioned in the previous section, empirical tests are made difficult almost irrespective of area - by two pervasive problems: the measurement problem (the multifaceted nature of the transparency concept makes it difficult to convincingly pin down quantitatively), and the endogeneity problem (transparency is strongly correlated with institutional quality and economic performance in general, and these are likely to be co-dependent over time, introducing identification difficulties also cross-sectionally).

Empirical studies of aggregate effects of policy-related transparency include, e.g., Hameed (2005), who develops indicators of fiscal transparency based on the IMF (2007), and finds them to be positively associated with credit ratings and greater fiscal discipline, and negatively related to the level of corruption. Alt and Lassen (2006), in turn, find greater fiscal transparency to be associated with lower public debt and lower deficits. Glennerster and Shin (2008) use a narrow measure of economic policy transparency based on the accuracy and frequency of macroeconomic data released to the public (i.e., transparency of policy outcomes). They exploit an exogenous shift in the procedures for reporting macroeconomic data to the IMF to identify causality, and find that adopting the IMF's new and more transparent regime for data release results in significantly lower government borrowing costs.

Gelos and Wei (2005) study the effects of both corporate transparency (measured as an index of perceptions of the quality of financial disclosure) and government transparency (encompassing both the predictability of macroeconomic policies and the frequency and timeliness of macroeconomic data releases) on the portfolio allocations of international emerging-market mutual funds. Their results indicate higher portfolio holdings of institutional investors in more transparent countries, as well as a higher propensity by these investors to retract investment from less transparent countries in times of crisis. Brandão-Marques et al. (2013) measure “country transparency” in several different ways, including corporate disclosure, indices of the transparency of government policies, and more indirect indicators such as 
perceptions of corruption. They find that emerging-market countries that are less transparent significantly and consistently react more strongly to global financial shocks than countries that are more transparent, both in terms of changes in bond spreads and stock market returns.

Broader measures of transparency have been used to study its effects on, e.g., foreign direct investment (FDI) inflows (Drabek and Payne, 2001), FDI as well as portfolio capital and bank lending inflows (Hooper and Kim, 2007), and economic growth (Williams, 2007). These studies generally support the expectation of a positive correlation of transparency with capital inflows and growth.

In summation, available empirical results appear by and large consistent with the intuition that greater transparency is associated with a host of benefits: greater transparency (policy as well as corporate) is associated with higher-quality and more efficient institutions; greater corporate transparency is associated with lower capital costs, betterdeveloped financial markets and greater capital allocation efficiency; and countries with more transparent policies and institutions have lower borrowing costs, receive more direct and portfolio investment inflows, and are more resilient to international financial shocks. In the next section, we address the question whether more transparency is always better.

\section{Optimal transparency}

The importance of efficiency gains as a rationale for and a hoped-for effect of transparency, as well as constrained Pareto efficiency as the standard criterion for determining whether such efficiency gains can be achieved, suggests a simple and intuitive way of thinking about how much transparency is motivated: simply that (welfare) benefits of greater transparency to sender and receiver of information have to outweigh the costs. Because reducing information asymmetries is generally costly, more transparency is not necessarily always better. 
This section offers a few examples of research that addresses the question of “optimal transparency” from this point of view. The examples send a nuancing message about the blessings of increased transparency, and might be thought of as caveats to the general message of the previous section that greater transparency is beneficial: it is, mostly, but not unconditionally. To structure the discussion, we observe that costs may occur both on the sender/supplier side (the production and dissemination of information is costly, and revealing information may have indirect costs), and on the receiver/demand side (the processing of information is costly, and the more so the less precise the information is).

It is worth pointing out that several of the (empirical) contributions already discussed find that the benefits of transparency may be concave. For instance, in the area of corporate transparency, Leuz and Verrecchia (2000) argue that if the disclosure environment is already rich, further increases in disclosure may have little effect on firms’ cost of capital. This argument is consistent with the findings in Greenstone et al. (2006) for corporate transparency, and Glennerster and Shin (2008) for fiscal policy transparency, among others. Similarly, Plummer and Tafti (in Forssbaeck and Oxelheim, forthcoming, Chapter 7) find that the available evidence suggests that developing countries (where transparency in trade policy is generally lower) have the most to gain by increasing transparency. In short, several studies confirm the intuition that the benefit to increasing transparency is marginally decreasing. The contributions discussed below take this one step further, and suggest that the net benefit of transparency is not just a marginally decreasing positive function, but that the function may turn negative beyond some point, suggesting a possible optimum.

We start with arguments focusing on the cost to the sender of making private information public. A starting point might be the simple example briefly mentioned in Section 2, where the net benefit of corporate transparency is the sum of the efficiency gain of reducing information asymmetries vis-à-vis investors and the loss of revealing competitive advantages 
to rival firms. The idea is formalized by, e.g., Admati and Pfleiderer (2000), who take as their point of departure the basic premise that lower information asymmetries between firms and investors are associated with higher firm value, lower cost of capital, and generally more efficient financial markets. But why, then, don’t firms voluntarily disclose all relevant information, and why is disclosure regulation necessary? In their model, the answer is that disclosure is costly. More precisely, there are both direct costs of information production and dissemination, which is likely to increase in the precision of the information, and indirect costs in the loss of competitive advantage or bargaining power entailed in revealing strategically important information to competitors, customers, or suppliers.

Sadka (2004) provides a related example, where corporate transparency can increase economic growth by allowing competing firms to share useful information about production technologies, thus raising productivity in an entire industry. But too much transparency reduces incentives to undertake investments that improve production processes, because the competitive advantage created by the investment will be revealed and the investing firm unable to exploit it. The basic driver of the result is thus a free-rider problem similar to the one motivating protection of patents and other intellectual property rights (see, e.g., Kanwar and Evenson, 2003). Ruigrok et al. (in Forssbaeck and Oxelheim, forthcoming, Chapter 18) investigate the same type of tradeoff in the context of governance transparency. Firms’ preferences regarding transparency about the characteristics of their boards of directors and management is determined by a tug of war between the benefits of reducing information asymmetries (e.g., signaling ability and compliance with norms and regulation) and the risk of "human capital attrition” (i.e., revealing competitive strengths or losing key talent).

These examples focus on corporate transparency, but it is worth pointing out that the basic structure of the problem goes well beyond that of optimal disclosure for firms 
and the potential loss of competitive advantage. ${ }^{12}$ For instance, Gugler (in Forssbaeck and Oxelheim, forthcoming, Chapter 6) addresses competition policy transparency, where too much procedural transparency may harm the efficiency of antitrust law enforcement (potential examples in other policy areas abound). The key point is that there may be a (social) value to secrecy that outweighs the benefits of transparency.

Besides direct and indirect costs to the sender, (involuntary) transparency also has incentive effects based on the value to the sender of private information. For instance, in Hermalin and Weisbach (2012), improved information disclosure by firms leads to better monitoring by owners, but may also incentivize managers to engage in costly activities intended to (falsely) signal ability, and to demand higher compensation in return for the stricter monitoring. The ultimate effect may be a reduction in firm value.

A related effect is discussed by Begg (in Forssbaeck and Oxelheim, forthcoming, Chapter 4) in the context of fiscal policy transparency and fiscal rules. He argues that a potential adverse effect of improved monitoring based on nominal measures of transparency may be that policy-makers focus on what is subject to scrutiny rather than on what is achieved, resulting in suboptimal policy outcomes. The effect has very broad potential application to monitoring and evaluation in general. The fundamental point is that increased ex ante transparency (leading to improved observability of "effort”) when the principal does not know what the appropriate behavior is to attain the best possible outcome may be harmful by encouraging the agent to "play it safe" and act according to the public belief of what is best,

\footnotetext{
${ }^{12}$ Consider the insurance market, for instance, extensively studied in the adverse selection literature (e.g., Rothschild and Stiglitz, 1976; Wilson, 1977). Insurance companies would like to know as much as possible about the insured, possibly including individuals’ genetic predisposition for certain diseases, but to many people, the integrity costs of divulging this type of information (assuming it is available) would be simply unacceptable, regardless of how much more efficient it could make the insurance market.
} 
even though he knows it is wrong, for fear of punishment (see Prat, 2005; for an alternative view, see Fox and Van Weelden, 2012).

Yet further go models where the sender's incentives depend directly on the information transmitted, such as principal-agent models of the owner-manager relationship where the manager's compensation depends on the stock price, and the stock price depends both on the manager's effort and on the firm's disclosure, which is controlled by the manager. In the traditional principal-agent setup, where stock price (and therefore compensation) depends only on the manager's effort, incentive pay based on stock price performance should align the manager's incentives with the owner's, but if the information contained in the firm's disclosure also influences compensation, the manager may have incentives to misrepresent or distort the information.

Goldman and Slezak (2006) study this setup, and find that incentive pay based on stock price performance in this case may lead to resource diversion and decreased firm value. They also find that an exogenous requirement to improve disclosure can actually increase the amount of information manipulation by decreasing "internal” monitoring by the principal, suggesting that regulation to increase disclosure may not unambiguously increase de facto transparency. Their findings are related to "signal-jamming” models, where an agent takes a costly action intended to mislead, and although the action does not actually mislead anyone, it leads to an inferior outcome.

Rather than the costs of information provision or the incentive effects for the sender, other stories about the mixed blessings of transparency focus on the quality of the information and/or the (limited) ability of the receiver to process the information. The simplest argument in this vein is just that information processing is costly - "too much" transparency may simply overwhelm receivers by information overload. This basic argument takes many forms and nomina - “excess baggage”, “clutter” (see e.g., Forssbaeck and Oxelheim, 
forthcoming, Chapter 22), the "veil of transparency" (hiding inappropriate action behind a wealth of information), etc. - and recalls the distinction we made in Section 2 between the quantity and the quality of information, as well as our insistence that transparency has a receiver as well as a sender side. Drowning the receiver in information - much of which is irrelevant - cannot be considered “transparent” by these standards. But what if the information transferred by its very nature is "noisy”?

One of the areas where the mixed effects of transparency have been most intensely debated is that of coordination games where private information is asymmetrically distributed among multiple agents and public information is imprecise. The most influential contribution is that of Morris and Shin (2002), which has given rise to a line of subsequent papers that study the dual role of public information. The first of these roles is that as purveyor of knowledge about "fundamentals" which is of value for decisions simply by reducing uncertainty and increasing the efficiency of the decision. The second role of public information is that of a coordination device. When decisions are not taken in isolation, based on the best available information pure and simple, but are complementary to the decisions of others, then it may start paying off to try to anticipate, or imitate, the reactions of these other agents to public information announcements - that is, people start to pay attention not only to what they know, but what they think others might know.

Morris and Shin (2002) mostly use as example of this guessing game the central bank giving out public signals about its intentions regarding policy, to which financial markets attach “too much” weight. Another example might be the release of public firms’ financial statements: analysts must not only analyze fundamentals in the reports, but also attempt to second-guess the average reaction of other analysts to the release in order to cover their bets.

Again, public information plays a double role: both that of provider of knowledge about fundamentals, and that of something to rally around, something which - 
though imprecise - may still have meaningful economic consequences and be optimal to take into consideration from the point of view of the individual decision maker. Boot et al. (2006) provide yet another example in the shape of financial market reactions to credit rating announcements. These convey imperfect information, but serve as “focal points” for market participants.

Increasing transparency by release of imprecise information can be beneficial by coordinating market participants' expectations, but “it also has the potential to do ill if expectations are coordinated away from fundamentals” (Morris and Shin, 2002, p. 1523). The argument resembles the one underpinning theories of, e.g., asset price bubbles by way of "herding” behavior, or “information cascades” (e.g., Banerjee, 1992, and Bikhchandani et al., 1992). Each decision maker acts rationally toward the possibility that someone else may have better private information, giving the result that everybody under-weights the information on fundamentals available to him- or herself. The overall outcome is inefficient, because the total body of available information is under-used. These results, however, are generally relatively sensitive to the exact assumptions made. As an example, consider how Angeletos and Pavan (2004) or Hellwig (2005) reach almost the opposite results of Morris and Shin (2002), essentially just by making a few alterations in the assumption of how complementarity between agents' actions works.

Other examples of situations where imprecision in the information transferred or market distortions can cause transparency to reduce efficiency are given by Geraats (2002), and Albornoz et al. (2014). In the former, the holder of the private information is a public body (again, the primary application is monetary policy, but in principle, the result can be generalized), which takes policy action according to (or reveals a signal about) a variable of interest, $x$, whereas the private sector forms expectations about this variable. If the central bank is uncertain about $x$, then being transparent about this uncertainty can be welfare- 
reducing by increasing the volatility of the private sector's expectations about $x$. In other words, the uncertainty of the authorities feed into the uncertainty of the public, making transparency cause a reduction in efficiency.

To sum up, because reducing information asymmetries is generally costly, greater transparency is not always better. Costs may appear both on the sender and on the receive side. To the sender of information, costs may be direct or indirect. When it comes to the receiver side, the precision of the information transferred proves to be of central importance both because information processing costs are negatively related to the precision of the information, and because of the increased possibilities that imprecise public information may cause coordination failures.

\section{Conclusions on the multi-faceted concept of transparency}

In recent decades transparency has emerged as a proposed remedy of many economic problems - be it to avoid corporate scandals, to increase the competitiveness in sluggishlyperforming economies, or to prevent financial crises. There is a common belief that greater transparency is good. In this chapter we have made an effort to sort out what transparency is actually about by pin-pointing common denominators of different definitions, and also to challenge this general positive belief by acknowledging the notion of optimal transparency, i.e. recognizing the concave feature of the value of transparency.

We began with the observation that the meaning of the concept of transparency varies between users and between contexts. Nonetheless, there are a few common denominators of that need to be considered in all discussions about transparency. The first is the existence of an information asymmetry. In addition, there needs to be a mechanism to transfer information from the informationally advantaged to the informationally disadvantaged - i.e., from "sender" to "receiver". We addressed the character of the information content and sug- 
gested that information about quality and intent are the most important generic types for $e x$ ante transparency, and that information about outcome constitutes ex post transparency.

Transparency is often confused with mere disclosure of information. In our view, there is an important distinction in that transparency has a demand-side dimension as well. This means that the information transferred should be not only observable but also relevant to the receiver, trustworthy, and sufficiently precise, which boils down to the criterion that the receiver attaches a value to the information transferred.

We then argued that transparency has to be linked to an objective function, i.e. some sense of what transparency is good for. Two main types of objectives were suggested. The first (and, for economic research, the main) one is functional, or instrumental - transparency as a means to an end. Efficiency is the key word. Efficiency gains are attained both through ex ante transparency, focusing on predictability, and ex post transparency, focusing on enforcement and disciplining. The second main type of objective is more "ideological" or value-driven and concerns ideals like democratic accountability or legitimacy, but also adherence to social contracts and norms within a society. We are here much closer to transparency as an end in itself - transparency as a "right to know".

The observation that actual levels of transparency vary greatly across policy areas, countries, markets, and companies made us ask for the determinants of transparency. We argued that the incentives facing the actors, relative costs and benefits of making information available, and (exogenous) regulations mandating a certain level of transparency to be key determinants. But also social norms and perceptions of what is "fair" and "right” appear to be interacting with the actual levels of transparency observed, possibly suggesting complementarity and co-dependence between transparency and things like trust and general institutional and governance quality. Such complementarities present empirical studies aimed at disentangling what causes what with considerable identification problems. 
Of the different objective functions discussed for transparency we pursued the “efficiency rationale” into a discussion about the potential effects of increased transparency. Interpreting increased transparency as reductions in information asymmetries implies that its effects are the reverse of the question of what problems information asymmetries give rise to. These are of two main types: selection and agency problems, associated with imperfect ex ante transparency, and accountability or enforcement problems, associated with imperfect ex post transparency. These two types of problems are pervasive in all areas of economic research and their consequences very diverse - market incompleteness, imperfect competition, transaction and uncertainty costs, coordination failures, etc.

We suggested a variety of channels through which increased transparency, by increasing predictability (ex ante) and contract enforceability (ex post) may impact aggregate outcomes such as economic growth. A key channel is the interaction of corporate and institutional transparency in facilitating investment in innovation and knowledge. Again, complementarities between different types of transparency are central, and the policy implication is that regulators and governments have a reason to be concerned not only with their own transparency but with corporate transparency as well.

This also means, however, that empirical evidence on the effects of transparency is marred by endogeneity problems (due to the co-dependence of transparency and institutional quality and economic performance), as well as measurement problems (the transparency concept is difficult to measure quantitatively). Available studies of transparency in specific areas do, however, appear to support the general view that greater transparency is associated with a number of benefits such as - at the policy level - more efficient institutions and - at the corporate level - lower cost of capital and greater capital allocation efficiency. Studies also indicate that countries with more transparent policies and institutions have lower borrowing 
costs, make better public spending decisions, receive more direct and portfolio investment inflows, and are more resilient to international financial shocks.

The final question we addressed is whether more transparency is always better. The question is relevant since reducing information asymmetries is generally costly. Much of the existing research suggests that the net benefits of transparency describe a concave function. Other studies show that the marginal benefit of increased transparency may even turn negative beyond some point, suggesting a possible optimum. Costs of increased transparency occur on the sender side both as direct costs of information production and dissemination, and as indirect costs in the form of, for instance, loss of competitive advantage or bargaining power from revealing additional information. Moreover, in, e.g., competition policy or insurance markets there may be social value to secrecy that outweighs the benefit of transparency. In addition to direct and indirect costs to the sender there may be incentive effects based on the value of the information to the sender. Some of these, we argue, may have the ultimate effect of reducing firm value. In some cases - like in the case of CEO compensations - the sender's incentives may depend directly on the information transmitted.

On the receiver side, there are costs of information processing that may weigh on the benefits of increased transparency, but the notion of optimal transparency is also supported by the dual role of (imprecise) public information. The first role is to disseminate knowledge about "fundamentals" in order to reduce uncertainty whereas the second role is that of a coordination device. These two roles together make people pay attention not only to what they know but also what they think others might know, giving rise to possible coordination failures in the form, e.g., of herding behavior. From a policy-implication point of view, this implies that there might be a cost of guiding the receiver too far by making noisy information public. 
All in all, our paper supports the existence of different definitions of transparency across policy areas, institutional settings, industries, and possibly also across individual firms. The bottom line of the paper is that the meaning of "optimal transparency" will also differ across these categories.

\section{References}

Admati, A. R. and P. Pfleiderer (2000), “Forcing Firms to Talk: Disclosure Regulation and Externalities”, Review of Financial Studies 13(3), 479-519.

Aghion, P., Y. Algan, P. Cahuc, and A. Shleifer (2010), “Regulation and Distrust”, Quarterly Journal of Economics (August), 1015-1049.

Akerlof, G. A. (1970), “The Market for “Lemons”: Quality Uncertainty and the Market Mechanism”, Quarterly Journal of Economics 85, 488-500.

Albornoz, F., J. Esteban, and P. Vanin (2014), “Market Distortions and Government Transparency”, Journal of the European Economic Association 12(1), 200-222.

Alt, J. E. and D. D. Lassen (2006), “Fiscal transparency, political parties, and debt in OECD countries”, European Economic Review 50, 1403-1439.

Angeletos, G.-M. and A. Pavan (2004), 'Transparency of Information and Coordination in Economies with Investment Complementarities’, American Economic Review 94(2) (Papers and Proceedings): 91-98.

Banerjee, A. V. (1992), ‘A Simple Model of Herd Behavior’, Quarterly Journal of Economics 107(3): 797-817.

Barro, R. (1991), ‘Economic Growth in a Cross-Section of Countries’, Quarterly Journal of Economics 106(2): 407-43. 
Barro, R. (1997), Determinants of Economic Growth: A Cross-Country Empirical Study. Cambridge, MA: MIT Press.

Besley, T. (2007), Principled Agents? The Political Economy of Good Government. Oxford: Oxford University Press.

Bikhchandani, S., D. Hirshleifer, and I. Welch (1992), ‘A Theory of Fads, Fashion, Custom, and Cultural Change as Informational Cascades', Journal of Political Economy 100(5), $992-1026$.

Boot, A. W. A., Milbourn, T. T., Schmeits, A. (2006), “Credit Ratings as Coordination Mechanisms”, Review of Financial Studies 19, 81-118.

Brandão-Marques, L., G. Gelos, and N. Melgar (2013), “Country Transparency and the Global Transmission of Financial Shocks”, IMF Working Paper No. 13/156, Washington: IMF.

Bushman, R. M., J. D. Piotroski, and A. J. Smith (2004), “What Determines Corporate Transparency?” Journal of Accounting Research 42(2), 207-252.

Chevalier, J. and D. Scharfstein (1996), “Capital-Market Imperfections and Countercyclical Markups: Theory and Evidence”, American Economic Review 86, 703-725.

Coase, R. H. (1960). “The Problem of Social Cost”, Journal of Law and Economics III, 1-44.

Connelly, B. L., S. T. Certo, R. D. Ireland, and C. R. Reutzel (2011), “Signaling Theory: A Review and Assessment”, Journal of Management 37(1), 39-67.

De Long, J. B., A. Shleifer, L. H. Summers, and R. J. Waldmann, 1990b, Noise trader risk in financial markets, Journal of Political Economy 98, 703-738.

De Soto, H. (2012). “Live, Dead, and Fictitious Capital”, keynote address delivered at the World Bank ABCDE Conference on Accountability and Transparency for Development, May, 2012, Washington, D.C. 
Diamond, P. and R. E. Verrecchia (1991), “Disclosure, Liquidity, and the Cost of Capital”, Journal of Finance 46(4), 1325-1359.

Drabek, Z. and W. Payne (2001), “The Impact of Transparency on Foreign Direct Investment”, Staff Working Paper ERAD-99-02, Geneva: WTO.

Easley, D. and M. O’Hara (2004), “Information and the Cost of Capital”, Journal of Finance 59(4), 1553-1583.

Economist (2012), “The best disinfectant”, May $26^{\text {th }}$.

Forssbæck, J. and L. Oxelheim (2006), “Transparency, capital formation, and economic growth”, in L. Oxelheim (ed.), Corporate and Institutional Transparency for Economic Growth in Europe, Amsterdam: Elsevier.

Forssbæck, J. and L. Oxelheim (2011), “Corporate financial determinants of foreign direct investment”, Quarterly Review of Economics and Finance 51(3), 269-282.

Forssbæck, J. and L. Oxelheim, forthcoming, The Oxford Handbook of Economic and Institutional Transparency, New York: Oxford University Press

Fox, J. and R. Van Weelden (2012), “Costly transparency”, Journal of Public Economics 96, 142-150.

Frey, B. S. (1990), 'Institutions Matter: The Comparative Study of Institutions’, European Economic Review 34, 443-49.

Frey, B. S. (1998), Not Just for the Money: Economic Theory of Personal Motivation. Cheltenham: Edward Elgar.

Gelos, G. and S.-J. Wei (2005), “Transparency and International Portfolio Holdings”, Journal of Finance 60(6), 2987-3020.

Geraats, P. (2002), ‘Central bank Transparency’, Economic Journal 112 (November), F532-65. 
Glennerster, R. and Y. Shin (2008), “Does Transparency Pay?” IMF Staff Papers 55(1), 183209.

Goldman, E. and S. L. Slezak (2006), “An equilibrium model of incentive contracts in the presence of information manipulation”, Journal of Financial Economics 80, 603-626.

Greenstone, M., P. Oyer, and A. Vissing-Jorgensen (2006), “Mandated Disclosure, Stock Returns, and the 1964 Securities Acts Amendments”, Quarterly Journal of Economics 121, 399-460.

Greenwald, B. and J. E. Stiglitz (1986), “Externalities in Economies with Imperfect Information and Incomplete Markets”, Quarterly Journal of Economics 101, 229-264.

Hameed, F. (2005), “Fiscal Transparency and Economic Outcomes”, IMF Working Paper No. WP/05/225, Washington, D.C., International Monetary Fund.

Healy, P. M. and K. G. Palepu (2001), “Information asymmetry, corporate disclosure, and the capital markets: A review of the empirical disclosure literature”, Journal of Accounting and Economics 31, 405-440.

Hellwig, C. (2005), 'Heterogenous Information and the Welfare Effects of Public Information Disclosures', Working Paper (October), UCLA.

Hermalin, B. E. and M. S. Weisbach (2012), “Information Disclosure and Corporate Governance”, Journal of Finance 67(1), 195-233.

Hollyer, J. R., B. P. Rosendorff, and J. R. Vreeland (2011), “Democracy and Transparency”, Journal of Politics 73(4), 1-15.

Holmström, B. (1979), “Moral hazard and observability”, Bell Journal of Economics 10(1), 74-91.

Hooper, V. and S.-J. Kim (2007), “The determinants of capital inflows: Does opacity of recipient country explain the flows?” Economic Systems 31, 35-48. 
Hubbard, R. G. (1998), “Capital-Market Imperfections and Investment”, Journal of Economic Literature 36, 193-225.

IMF (2007), Code of Good Practices on Fiscal Transparency, Washington: IMF

Irlenbusch, B. and D. Sliwka (2005), “Transparency and reciprocal behavior in employment relations”, Journal of Economic Behavior and Organization 56, 383-403.

Jensen, M. C. and W. H. Meckling (1976), 'Theory of the Firm: Managerial Behavior, Agency Costs and Ownership Structure’, Journal of Financial Economics 5, 305-360.

Kanwar, S. and R. Evenson (2003), 'Does Intellectual Property Protection Spur Technological Change?' Oxford Economic Papers 55(2), 235-64.

La Porta, R., F. Lopez-de-Silanes, A. Shleifer, and R. Vishny (1998),’Law and Finance”, Journal of Political Economy 106, 1113-1155.

Leuz, C. and C. Schrand (2009), “Disclosure and the cost of capital: Evidence from firms’ responses to the Enron shock”, NBER Working Paper No. 14897, Cambridge, MA: National Bureau of Economic Research.

Leuz, C. and R. E. Verrecchia (2000), “The Economic Consequences of Increased Disclosure”, Journal of Accounting Research 38, 91-124.

Lucas, R. E. Jr. (1988), 'On the Mechanics of Economic Development', Journal of Monetary Economics 22, 3-42.

Matthews, R. C. O. (1986), 'The Economics of Institutions and the Sources of Growth', Economic Journal 96(384), 903-18.

Morris, S. and H. S. Shin (2002), ‘Social Value of Public Information’, American Economic Review 92(5), 1521-34. 
North, D. C. (1990), Institutions, institutional change and economic performance. Cambridge: Cambridge University Press.

OECD (2002), OECD Best Practices for Budget Transparency, Paris: OECD.

Perotti, E. and E.-L. von Thadden (2005), “Dominant Investors and Strategic Transparency”, Journal of Law, Economics, and Organization 21(1), 76-102.

Prat, A. (2005), “The Wrong Kind of Transparency”, American Economic Review 95(3), 862877.

Riley, J. G. (2001), “Silver Signals: Twenty-Five Years of Screening and Signaling”, Journal of Economic Literature 34, 432-478.

Rochet, J.-C. and X. Vives (2004), “Coordination Failures and the Lender of Last Resort: Was Bagehot Right After All?” Journal of the European Economic Association 2, 11161147.

Rodrik, D., A. Subramanian, and F. Trebbi (2004), 'Institutions Rule: The Primacy of Institutions Over Geography and Integration in Economic Development', Journal of Economic Growth 9, 131-65

Romer, P. M. (1986), ‘Increasing Returns and Long-Run Growth’, Journal of Political Economy 94(5), 1002-37.

Romer, P. M. (1990), 'Endogenous Technological Change’, Journal of Political Economy 98(5), pt. 2, S71-S102.

Rothschild, M. and J. E. Stiglitz (1976), “Equilibrium in Competitive Insurance Markets: An Essay on the Economics of Imperfect Information”, Quarterly Journal of Economics 90(4), 629-649.

Sadka, G. (2004), 'Financial reporting, growth, and productivity: Theory and international evidence', Working Paper, Columbia Business School. 
Sala-i-Martin, X., B. Bilbao-Osorio, J. Blanke, M. Drzeniek Hanouz, T. Geiger, and C. Ko (2013), ’The Global Competitiveness Index 2013-2014: Sustaining Growth, Building Resilience”, Global Competitiveness Report 2013-2014, Geneva: World Economic Forum.

Spence, M. (1973), “Job Market Signaling”, Quarterly Journal of Economics 87(3), 355-374.

Spence, M. (2002), “Signaling in Retrospect and the Informational Structure of Markets”, American Economic Review 92(3), 434-459.

Stiglitz, J. E. (1999), “On Liberty, the Right to Know, and Public Discourse: The Role of Transparency in Public Life”, Oxford Amnesty Lecture, Oxford, U.K., January 27.

Stiglitz, J. E. (2000), “The Contributions of the Economics of Information to Twentieth Century Economics”, Quarterly Journal of Economics (November), 1441-1478.

UNCTAD (2012), “Transparency”, UNCTAD Series on Issues in International Investment Agreements II, Geneva: United Nations.

Wehner, J. and P. De Renzio (2013), “Citizens, Legislators, and Executive Disclosure: Political Determinants of Fiscal Transparency”, World Development 41, 96-108.

Williams, A. (2007), “A Global Index of Information and Political Transparency”, Discussion Paper No. 14.07, University of Western Australia.

Wilson, C. (1977), “A Model of Insurance Markets with Incomplete Information”, Journal of Economic Theory 16(2), 167-207.

Wurgler, J. (2000), 'Financial markets and the allocation of capital', Journal of Financial Economics 58, 187-214. 